\title{
All Bleeding Stops, Eventually (But: The Sooner The Better!)
}

\author{
Curt Tribble, Lam Pham, Nicholas Teman
}

Division of Cardiac Surgery, University of Virginia, Charlottesville, VA, USA

\section{INTRODUCTION...FIRST DAY IN THE CT ICU}

It's your first day as the surgery resident working in the cardiac surgery intensive care unit (ICU) and you are accepting the hand off of a cardiac surgery patient that your senior resident has brought up from the operating room for admission to the ICU. During the handoff, your resident colleague tells you that the patient is 'oozing a lot' and that the operating team, after a diligent search for bleeding sites, does not believe that the oozing is 'surgical.' She announces that your job will, therefore, be to stop the ongoing oozing, while, of course, being alert to the possible development of tamponade physiology.

She asks you if you are 'up to the challenge,' and you assure her that you are (with the bravado that you know is expected of you). Not wanting to leave too much to chance, she asks you what your strategies will be. You confidently list the "usual suspects" in this setting, including dysfunctional platelets and elevated pressures (arterial and venous). You also assure her that you will obtain coagulation tests and treat any abnormalities that they reveal.

Your colleague nods approvingly and then says "that plan will be a good start, but I'm going to tell you about some additional strategies that are surprisingly important but that are often overlooked or not fully understood by those who haven't been in this unit before." She then says "let's go sit down in the conference room and review these additional approaches." She adds, "Bring your notebook so that you can take notes" reminding you of the old saying that "there are residents who write things down and there are residents who forget." She then points out the well-known educational adage that people remember things better when they write them down by hand, which, she notes, "is because handwriting activates more parts of both sides of the brain than does typing or reading the same words." [Tribble, 2016] She also promises to pass along some additional reading material afterwards, "to supplement our chat," invoking another principle of optimal learning, which is to see or hear the same concepts presented in different ways.

The two of you reconvene in the conference room, with some appropriate libations in hand, and your colleague starts

Correspondence: Curt Tribble, MD, Professor of Cardiothoracic Surgery, University of Virginia Health System, Division of Cardiac Surgery, Box 800679, Charlottesville, VA 22908; 434-243-9250 (e-mail: ctribble@virginia.edu). with a quick review of some priorities in a situation like this, such as ensuring that the chest tubes are stripped assiduously, the patient's blood pressure is controlled, the patient is kept sedated until the bleeding diminishes, and that coagulation labs are monitored and any abnormalities are treated. She then goes on to say, "as I mentioned earlier, there are a number of surprisingly important issues that are not as commonly thought of in this situation as they deserve to be, and we will review some of those issues in detail." Being the eager learner that you are, you assure her that you are always appreciative of 'pearls' of this sort.

\section{THE POSTOP TALK WITH THE FAMILY}

Your chief then starts by noting that she and the attending surgeon have just met with the patient's family and have told them that, while the operation itself has gone smoothly, the patient's blood is not clotting optimally yet, reminding them that this type of oozing is a common issue in heart surgery. And, she notes, they have also told the family that it is not uncommon for such patients to need a 'wash out' if enough blood accumulates that there is 'excessive pressure on the heart.' She says that it is best to give context to this sort of news by saying something like "this situation is not uncommon in cardiac surgery, and, if we do need to wash out the chest, we consider it to be 'all in a day's work' and the patient will not know that this additional procedure had been necessary until they wake up later, and we tell them about it." She points out that most families take some comfort in hearing the possibility of such a procedure explained in this way. You find this information valuable, as it might not have occurred to you how to optimally explain this situation to a worried family. [Tribble, 2017]

\section{MANAGING BLEEDING IN THE CARDIAC OPER- ATING ROOM: A VERY BRIEF INTRODUCTION}

Your chief reminds you that the operative team will have always done as much as they can to 'dry up' prior to closing. She, somewhat lightheartedly, says that the team always focuses on 'the six P's of hemostasis' which are: protamine, platelets, plasma (as in fresh frozen plasma), pressures, poikilothermia (as in warming), and Prolene, and adds "and, the greatest of these is Prolene," emulating the cadence and syntax of a well-known Bible verse. [I Corinthians 13] She notes that she can give you a detailed review of those intraoperative strategies at another time. 


\section{REVIEWING THE BASICS OF CHEST TUBE MANAGEMENT AFTER CARDIAC OPERATIONS}

Your chief goes on to say: "Now, we're going to talk about some of the surprising issues pertinent to a patient who is oozing or bleeding after cardiac surgery, but before we get to that, let's review some of the basic tenets of managing the chest tubes we use, some of which you likely already know." [von Hippel, 1970]

"There is actually quite a lot to know and tell about the number and the type we usually use and how we like to position them, but we'll also save that discussion for another time. For today, we'll dwell on the issues you need to know about them to take care of this patient at this particular time. The primary functions of the chest tubes are to evacuate any residual air and, more importantly, to drain blood and fluid from the mediastinum, so that tamponade physiology is avoided, while we work to get any ongoing oozing to subside. First of all, it's worth noting that the tubes are an important monitor of how much bleeding is occurring, moment to moment. Therefore, you should notice that the level of the blood in the tubes will 'oscillate' or fluctuate with each beat of the heart, but the level of the blood in the tubes should not advance with each heartbeat, because if it does, the patient will almost certainly need to be re-explored, likely expeditiously. However, if the blood level in the tubes advances only a bit with each breath delivered by the ventilator, the situation may not be quite so dire."

"Remember, too, if there is a 'dump' of blood (or bloody fluid) after repositioning the patient, that may not be an indication of on-going bleeding but, rather, may be the drainage of bloody fluid that, belatedly, has come in contact with the chest tubes. This scenario is particularly common when one, or both, of the pleural spaces has been opened, as is commonly true after a coronary artery bypass operation." [Elefteriades, 2013]

"Finally, if ongoing drainage from the chest tubes stops abruptly, particularly if the patient's blood pressure drops significantly, the patient is very likely to need to be reopened expeditiously. We'll talk more about this possibility and how to manage it in a bit, after we cover the strategies we'll employ to avoid the need for reopening the sternal closure."

"Any questions so far?"

You assure your colleague that you understand these principles and are confident that you can follow her instructions. She goes on to say "now, let's talk about some of the other important issues, which, if managed reasonably well, can avert the need for such aggressive moves."

\section{BASIC STRATEGIES TO EMPLOY IN A BLEEDING PATIENT}

"So, let's start with some basics. Obviously, you'll need to pay attention to treating the patient's blood pressure, as that pressure is, after all, the 'driving force' of most postop bleeding, which not infrequently comes from an aortic cannulation site, an aortotomy, needles holes in grafts, or the coronary anastomoses. However, there are several medications that are commonly used for blood pressure control that can impair optimal blood coagulation. Two of these medications are nitroglycerine and nitroprusside, both of which can inhibit platelet function. [Clark, 2012] If the patient's blood pressure does become higher than optimal, especially in a patient who is still oozing considerably, nicardipine is likely a better choice for controlling the arterial blood pressure. And, when a patient is having ongoing blood loss, we like to keep the patient sedated, not only to make managing their blood pressure easier, but also because we won't know for a while if a 'washout' will be necessary, and it won't help things if the patient is awake and agitated. An agent like propofol can be a good choice for sedation, as it is generally given as an infusion, which, of course, can be adjusted to achieve the optimal degree of sedation. I ran across this picture that I keep on my phone for chats like this, as it serves as a colorful reminder that we're looking to have 'just the right amount of pressure.' Here it is .....”

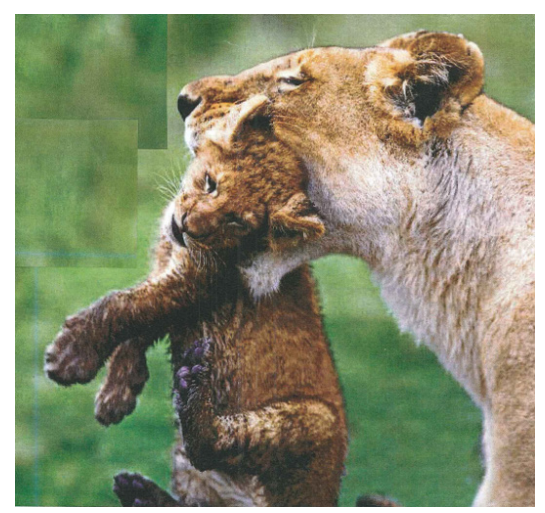

Your resident then points out that "similar to avoiding some antihypertensive agents that can inhibit platelets, there are also some volume expanders that should also be avoided, such as the hydroxyethyl starches, like Hespan. [Cope, 1997] Furthermore, once you think about it, you will realize that it's best to restrict the amount of crystalloid or albumin given in this setting, as these volume expanders can dilute the blood and coagulation factors excessively. Try to use blood components instead, both red cells and plasma, as well as platelets, for volume resuscitation, as needed.”

\section{LAB TESTS FOR A PATIENT BLEEDING AFTER CARDIAC SURGERY}

"Next, let's talk about the usefulness of certain lab tests in these postop cardiac patients. An ACT (activated clotting time) can help you assess the potential value of giving additional protamine, as sometimes not all the heparin given intraoperatively has been reversed. Regular coagulation tests (such as a PT and PTT) can be useful, too, though platelet counts may be of limited value, because the platelets will have been affected by exposure to the cardiopulmonary bypass circuit, as you likely know. If TEG (thromboelastography) is available, it can detect more specific coagulation issues, especially accelerated fibrinolysis. We'll talk more about TEG in 
a few minutes. Each of these tests and all of them considered together, can help guide your treatment of a persistently bleeding patient."

\section{EMPIRIC STRATEGIES FOR A PATIENT BLEED- ING AFTER CARDIAC SURGERY}

Your resident continues her introduction to managing bleeding in this setting, saying, "There are also some things that can be done empirically, such as giving extra calcium, especially if significant amounts of blood products have been given, because some of those blood products contain chelating agents, used as anticoagulants, and those agents will bind calcium. Therefore, giving some extra calcium, from time to time, can 'replace' the calcium that night be bound by the anticoagulant agents in the transfused blood products. And, it's helpful to know that calcium is also a bit of an inotrope and that you can give quite a lot of it, without worrying too much about giving too much."

"Now," your resident asks, "are you ready to relive some painful days of your basic science courses in the first year of medical school?" You shudder, acknowledging that those basic science courses were not your favorites in med school.

"You will need to keep the patient's $\mathrm{pH}$ as close to normal as you can, and the reason for that strategy is based on Michaelis-Menten kinetics, which you will, at least vaguely, remember from your first year biochemistry course. The reason that concept is important is that blood clotting is a biochemical process, and the kinetics of that process are affected by a wide array of factors, including the concentrations of the 'reactants,' the temperature of the milieu, and the $\mathrm{pH}$ of the environment, which is the blood in this situation. I also have a picture of a typical graph of these kinetics on my phone, which will, perhaps, remind you of those early days in med school. Here's an illustrative graph:"

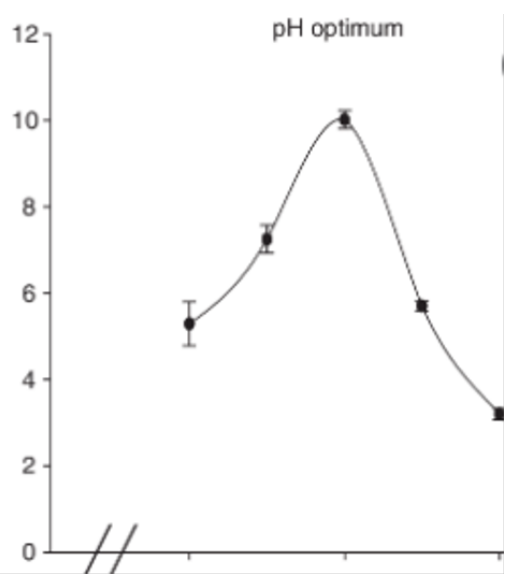

"As you will likely recall, all biochemical processes function optimally when they occur in a fairly narrow physiological range. Therefore, managing the $\mathrm{pH}$ of your patient will optimize the efficiency of the biochemical process of blood clotting. I emphasize this principle because it is easy to lose sight of the fact that coagulation is, indeed, a biochemical process subject to these sorts of conditions. The take-home message of this paragraph is that you need to keep the patient's $\mathrm{pH}$ in a physiologic range, with ventilation strategies, supplemented, when necessary, with bicarbonate administration. Does that make sense?"

You acknowledge that those principles do, indeed, make sense.

\section{IN COLD BLOOD}

She continues, "Now, we're going to talk about a number of strategies and issues for dealing with a bleeding patient that often don't make it into books like the one you say that you've been reading."

The next question your chief asks you is a bit off-putting to you. She asks "when you got beat up at school when you were a kid, what temperature water did your mother tell you to use to wash the blood out of your shirt?" As you look puzzled, she adds, "Now, the just right answer to that question is 'I never got beat up!' But, the actual correct answer to that question is cold water, because cold blood doesn't clot."

She continues, saying "as we've just discussed, blood coagulation is a biochemical process that follows Michaelis-Menten kinetics, and is, therefore, influenced by the same factors that affects all biochemical processes, with temperature being particularly important. In fact, coagulation is exquisitely sensitive to even mild hypothermia. So, we're going to talk about ways to warm up a bleeding patient to help slow or stop the bleeding."

"To begin with, it's worth noting that even though measures are always taken in the operating room to try to warm or rewarm the patient, the temperature of these patients virtually always falls, often significantly, by the time they make the road trip to and arrive in the ICU. There are some obvious things worth doing immediately, as, or before, the patient is moved to their ICU bed, including warming the room, closing the doors to keep heat in the room, using a Bair Hugger to cover as much of the patient's body as is feasible, and packing warm blankets around any body parts not covered by the Bair Hugger, especially the patient's head."

Your senior resident continues, saying that "you must also warm all fluids and blood products being administered, which can sometimes be challenging because blood warmers are often in short supply. If you don't have enough of them, one of the best places for 'scavenge' for them is in a pediatric intensive care unit. They almost always have extras, though you'll likely need to make all sorts of promises about how you'll personally bring them back, once your patient has been rewarmed." You acknowledge the necessity of being a good citizen of the institution in this way.

Your chief then goes on to note that there are a number of surprising impediments to warming a patient arriving in the ICU and says "Now let's review some of those issues ......"

"One of those issues is that most people, at least here in the United States, don't understand the metric system, at least not intuitively. That can be somewhat of a problem when talking about warming patients up, because it seems 
as though people are often oblivious to how cool fluids or blood products at room temperature (or below) are, compared to normal body temperature. You can illustrate that lack of familiarity with the metric system to them by asking them what 'room temp' is in centigrade degrees. They usually won't have a number on the tips of their tongues, and you can tell them that it's about 20 degrees. So, it's worth reminding everyone involved that all of the fluids or blood products being infused into a patient who is continuing to bleed need to be warmed." You nod to affirm that you're hearing this message 'loud and clear' and assure her that you will make sure that all the fluids and products being administered will be run through warmers.

She then asks how you might warm these fluids and blood products if blood or fluid warmers are in short supply, which they often are. When you don't have a quick answer to that question, she points out that warming lights can be placed strategically around the patient so that they are directed at the bags of fluids and the tubing carrying the fluids. This strategy, when used, she notes, may not only warm the fluid and the patient, but they also serve to remind everyone that it's worth doing everything imaginable to warm the fluids and the patient.

Next, your chief surprises you with what seems like a question out of the blue, when she then asks "what common sport court has the same surface as that of the surface of the alveoli of a typical pair of human lungs?" After a moment's contemplation, you guess that a tennis court has about the same surface as that of the lungs, which turns out to be correct. She then asks you why that might be important in warming a hypothermic patient, and you confess that you have no idea. To explain this issue, she asks you what temperature you think the air and oxygen being used for ventilating this patient is, as those gases enter your patient's lungs. Again, having never contemplated that question, you guess "room temperature." She points out that those gases are usually considerably cooler than that, having been carried into the ICU room through pipes running underground and through the walls of the hospital, which likely makes them quite a bit cooler than room temperature. She goes on to point out that this gas mixture can be warmed with an in-line humidifier equipped with a warmer. Immediately you realize how effective warm air and oxygen could be in warming a patient, as every bit of blood in the patient's body will pass through the lungs every few minutes and will, therefore, be just a few microns from this warm gas mixture in the alveoli.

Then, your chief surprises you once more by asking, "At what temperature do you want to set the warmer on the humidifier?" Having never thought about that question either, you offer the answer of "What about normal body temperature?" She replies, "Don't you want the humidified air and oxygen to be as warm as might be safe?" You nod affirmatively. "So what is the highest temperature that you might consider using?" After some additional contemplation, you wonder aloud if setting the temperature on the humidifier at about the same temperature as the warmest air you yourself have breathed, growing up working on a farm in South Carolina, which is about 104 degrees Fahrenheit or about 40 degrees Celsius. "Bingo" your chief replies. And, she goes on to note that a typical sauna is often heated to over 70 degrees Celsius, and that even higher temperatures than that are considered safe to breathe. The two of you agree that the humidifier temperature could surely be safely be set at 39 or 40 degrees, or, probably, even a bit higher.

"Now," she says, "we've got a good all round plan for warming our patient up expeditiously." And, though you suspect she's being optimistic, she says "With the kind of ongoing oozing we are seeing in this patient, if you can get this patient's core temp up to 37.5 degrees, he will stop bleeding." She then confides that, if the patient is warmed to that temperature and if the bleeding has not subsided, the patient is likely to need a re-exploration. And, she notes that "if we do need to re-explore the patient at that point, we'll likely be able to find a bleeding site, as the generalized oozing will have subsided enough to allow us to visualize something that we need to put a stitch or two in."

You acknowledge that you'd never really realized how important warming a patient like this would be nor all the many ways to accomplish the goal of normalizing their body temperature. She ends with the oft heard quip of "that's why it's a six or seven year program, right?" You cannot help sheepishly acknowledging the truth of that axiom.

\section{BRICK WALLS AND BLOOD CLOTS: WHAT'S IN A BLOOD CLOT?}

Your chief tells you to turn to a fresh page in your notebook and says "Now, this next part is gonna take a while. I'll start with a question, which is: What's in a blood clot?" You glibly rattle off the primary constituents of blood, happy to be able to answer at least one question with conviction and you note that plasma, platelets, fibrin, and red cells are all important constituents of clots. "True dat!" your resident replies, which reminds you that she's originally from New Orleans. She then asks, "And what percentage of a normal clot is made up of red cells?" You guess that red cells might make up something like half of the bulk of a clot, with the rest of that clot consisting of platelets and fibrin. She says "let me tell you the story of the first time I was asked that question....."

She goes on to say that, when she was younger and in charge of organizing the teaching conferences for the residents and students, she had asked a hematologist who was an expert in coagulation disorders and who was a popular teacher to come to one of the conferences each year or two to talk about hypercoagulable states that are occasionally an issue in cardiovascular patients. He had previously accepted all such invitations, but this time he told her that he wanted to talk about hypocoagulable states instead. Your resident goes on to say that she wasn't quite sure what he would have to say that the residents didn't already know, given that they frequently took care of patients who were bleeding, often excessively. However, she notes, she accepted his offer, curious about what he might have to say.

She continues, "on the appointed day for the conference, the hematologist, Dr. Humphries, arrived and started the conference by asking the residents to look out the window of the conference room at the brick wall of a nearby building. $\mathrm{He}$ 
then asked them to guess what percentage of that wall was made up of bricks and what percentage was made up of mortar. The guesses were all over the place. Then the hematologist said, 'Come on everyone! It's obvious that the vast majority of that wall consists of bricks, probably making up about $90 \%$ of that wall!' Those present acknowledged the validity of that assertion, once they'd had a chance to reconsider their original answers. He then said, 'That's about the same percentage of a normal, functioning blood clot that is made up of red cells.' He then showed a couple of photomicrographs to illustrate his assertion. I was so impressed with this concept and with his images that I've kept those pictures on my iPhone." She whips her phone back out and shows you these pictures:
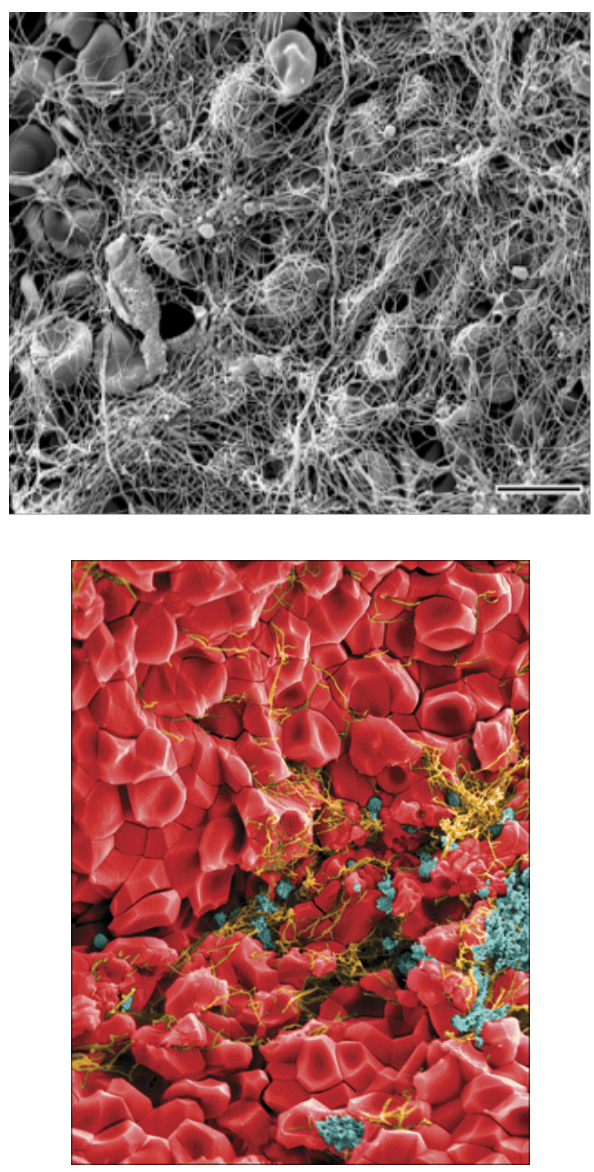

She then says: "You'll have to admit that the red cells make up the vast majority of the substance of these clots, right?" You acknowledge the validity of that observation. She then goes on to say that one of the other residents present that day asked Dr. Humphries what he thought the ideal hematocrit should be in a patient who was bleeding. Dr. Humphries said, "I'll quote one of my critical care heroes, Dr. Robert Bartlett at The University of Michigan, who, when asked about an 'ideal' hematocrit in patients on ECMO said 'I just go with God and Darwin and try to keep the hematocrit in such patients normal,' an assertion that always made sense to me." Your resident added "we've often focused on 'restrictive transfusion strategies' while thinking of disease transmission, cost control, and other similar issues. However, as Dr. Humphries taught us that day, these concerns are of a significantly lower priority in a patient who is actively bleeding." Your resident concludes "so, the take-home message is that we strive to transfuse enough red cells in a bleeding patient to keep their hematocrits relatively normal." You acknowledge the validity of that strategy, as you continue scratching away in your notebook. [Gersh 2009, Cines, 2014]

\section{OTHER COMPONENTS TO CONSIDER GIVING (OR RE-ADMINISTERING)}

Your chief resident tells you to start another new page in your notebook, which you dutifully do. She notes that she had started talking about 'component therapy' with the discussion of red cells, as, quite often, the red cells are, paradoxically, not considered to be part of 'component therapy,' despite being one of the most important components of clots. She then asks, "What do you think is the second most important blood component in a patient bleeding after heart surgery?" You sense that you have a chance to regain some lost ground in this discussion and answer "I am pretty sure that the answer to that question is platelets, because they are rendered dysfunctional by exposure to the membranes and surfaces of the heart lung machine." "Bingo," she says, as you heave a sigh of relief at seeming to be back on the right track. She goes on to ask what parameters you will use to guide your transfusion of platelets, and you, after a moment's hesitation, say that you believe that they should be administered empirically, since the platelet count will not be all that useful in this setting. Again, she acknowledges that you are correct, at least this time.

She then asks what else you think you'd be inclined to administer to a bleeding post-cardiotomy patient, and, feeling like you're on a roll, you say that you'd also give fresh frozen plasma (FFP), appropriately warmed during administration. She acknowledges the validity of that plan, also, noting that the trauma folks recommend that the ratio of FFP to packed red cells should be high, perhaps ideally between 1:1 and 1:2.

[Tibi 2021, Holcomb 2015, Hess 2021] She notes that the emphasis on administering FFP might be even higher if the patient had been on an oral anticoagulant like Coumadin prior to the operation, even if there had been a period of 'washout' prior to the operation.

"So, now that we've covered what most would consider to be the primary components of blood, is there anything else we need to think about giving the patient?" Once again, you're caught a bit off guard, not knowing what she's driving at. Anticipating that the answer might not be on the tip of your tongue, she answers her own question, saying that these patients often need more fibrinogen than might be anticipated. "What product do we give if we want to provide more fibrinogen?" You're happy that, at least once more, you think you know the answer, and you say "cryoprecipitate is what's needed to provide more fibrinogen." Your resident acknowledges that you are correct, and then asks if there's a way to gauge the need for cryo. Once again, you're unsure of the answer and acknowledge that you're not sure you know. "Sorting out the need for the administration of 
cryo is best done in these situations with TEG (Thromboelastography) or ROTEM (Rotational Thromboelastometry)," she points out. "Are you familiar with those devices?" she asks. You acknowledge that you have heard of them but are not all that familiar with them. She points out that the TEG or ROTEM machines are not familiar to many clinicians, as they are used primarily in the operating room by the cardiac anesthesiology teams. And, she notes, that, if the last test done with one of these devices in the OR suggested that the fibrinogen was 'on the low side,' it is certainly appropriate to give some cryo, even if some has already been administered. She goes on to say that recognition of the importance of cryo in cardiac surgical patients is more widely understood now that TEG or ROTEM testing is done more often than had been the case in the past.

\section{THE 'MEDICINE CABINET' FOR BLEEDERS (DRUGS TO CONSIDER GIVING)}

Once again, your resident suggests that you start a new page in your notebook, saying "now we'll talk a bit about some other medications or factor concentrates to consider administering to a patient bleeding after a cardiac surgical operation.

She says, "The first drug to contemplate giving, as we've discussed, is protamine. Do you know why we might give an extra dose of protamine empirically?" You acknowledge that you've heard that heparin might be 'washed out' of underperfused vascular beds, perhaps as the patient warmed up. She is happy you've heard of this concept, and she adds "while that may be true, it's also worth noting that there is little downside to giving at least some extra protamine to a bleeding patient, because the likelihood of a protamine reaction in a patient who has already received a dose without incident is quite low and because it might do at least some good."

"What else might we give the patient, at least somewhat empirically?" You ponder the question and suggest that additional antifibrinolytics might be worth giving, as, in a bleeding patient, there would likely be some loss of that drug in the chest tube effluent. Your chief likes that line of thinking, and nods her head and asks "are there any other drugs that come to mind that might be helpful?" You're about out of ideas at this point. She's not surprised and says so. She adds that there are some clinicians who think that DDAVP can be at least somewhat helpful in patients who may have some platelet dysfunction attributable to renal insufficiency, making it a reasonable consideration in such patients. [Salzman, 1986]

"Finally," your resident notes, "there are times when some of the newer factor concentrates may be considered, such as Factor VII, Factor IX, or Prothrombin Complex Concentrate. These concentrates are quite expensive, and we usually reserve them for the most complex of our bleeding patients, such as those in whom we've repaired an aortic dissection."

\section{THE VALUE OF CHECKLISTS}

Your resident then says "let's consider another important strategy for bleeding and potentially unstable patients after

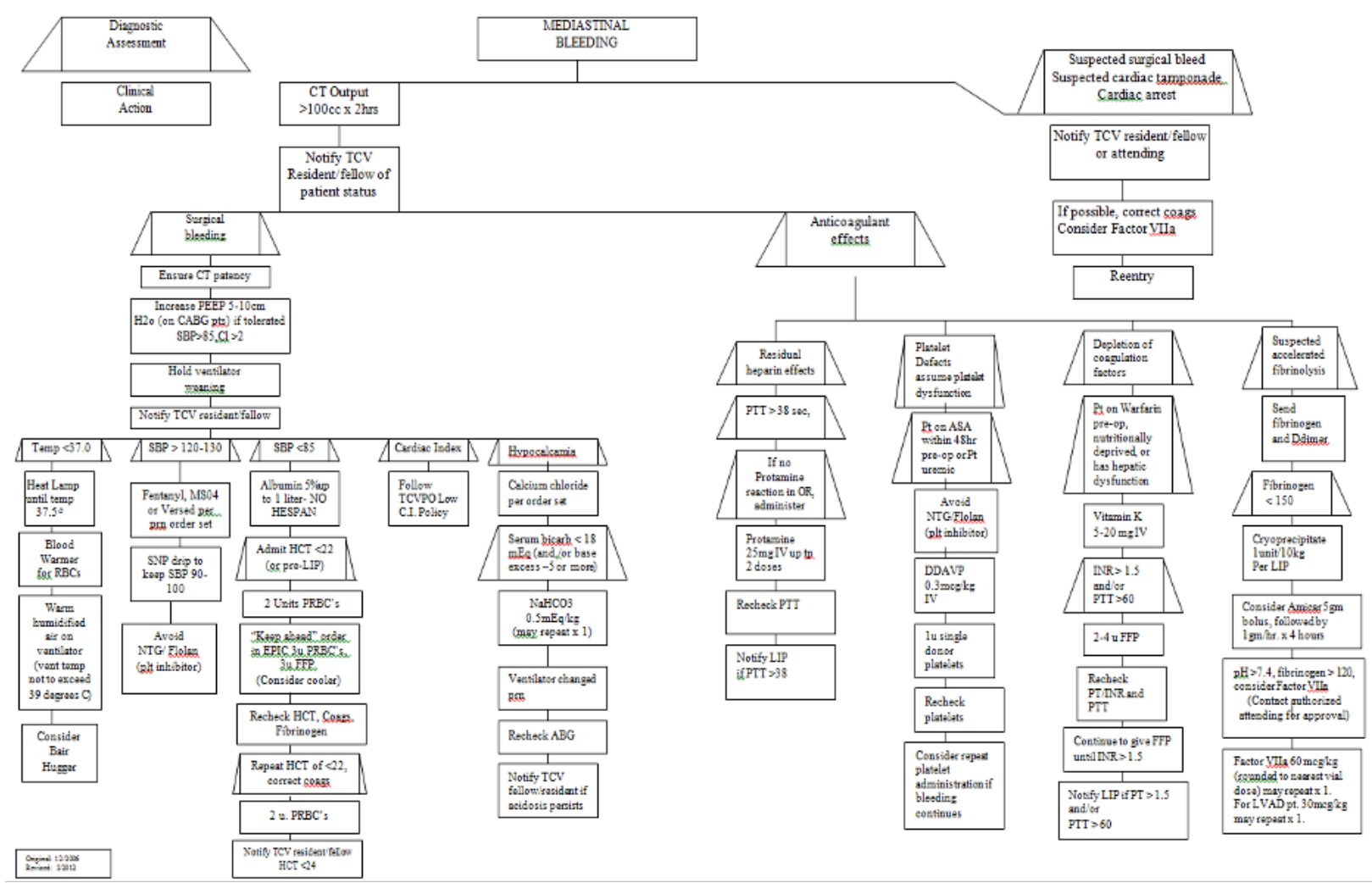


cardiac surgery. Since there are so many things to keep up with in a patient who is actively bleeding after cardiac surgery and since it's important to do as many of those things almost simultaneously, or at least as expeditiously as possible, it is usually worthwhile to have a checklist that everyone involved in the care of such a patient can follow along with together. There is a chart or checklist that has been used for many years here in our unit. I have a scaled down version of it that I keep on my phone, which I'll show you." You look at the chart that she shows you.

Your resident goes on to acknowledge that this version is a bit hard to read, but tells you that a PDF of the chart is kept in your unit's computer and can be printed out on oversized paper. She says "we like to print this more legible version of this checklist or algorithm out and tape it to the wall or door of the room of a bleeding patient, with hope that it will be 'a conversation piece' for everyone caring for a bleeding patient." She goes on to note that, at the very least, such a document can serve as a visual reminder to all that there are a great many things that can and should be considered in treating a coagulopathic patient who continues to bleed and that these issues need to be thought about and talked about, over and over, until the bleeding is under control, one way or another. Your resident can't help noting, with a touch of pride, that some of the earliest papers on the value of checklists in the surgical literature were written by surgeons at your institution. [Calland, 2002]

She continues, saying "we recognized that such a checklist or flow chart could provide what some call 'decision support' for the providers on the front lines, as you will be this evening. However, we later realized an additional, though subtle, benefit, which was that such a list or algorithm starts and promotes ongoing brainstorming among the team members. For instance, you, as the resident on duty, could look at this flow chart and ask your colleagues 'have we done, or have we considered doing, all the things on this chart?' As you can easily imagine, it is quite easy to get most of the things in one part of this chart done, while, perhaps, overlooking some important maneuvers or strategies displayed in a another part of it. Likewise, having this chart available can spark or guide conversations with your senior residents and faculty surgeons."

She continues, saying "obviously, the more different issues you have in play and the more strategies you must consider, and reconsider, the more valuable a well-designed flowsheet or checklist will be. And, this value increases even more when a lot of people are involved in a particular patient's care."

\section{KEEPING SCORE: IS THE PLEUREVAC HALF EMPTY OR HALF FULL?}

Your resident then points out, "needless to say, the bedside nurse will actually record the products given and the medications administered, but you, as the bedside resident, will need, as much or more than anyone, to keep looking at the chest tube output, the log of drugs and products given, the lab results, any imaging that's been done, and vital signs, while thinking moment to moment: what have we done and what should we do next? A patient's situation will, usually, begin to settle out in a good way or it will continue to be concerning. If the patient's bleeding seems to be continuing, we jokingly call that patient 'a free bleeder.' The value of such a declaration is that it can sometimes help replace a sense of complacency with a more appropriate level of concern. All this may seem a bit overwhelming on your first night in the unit. Do you think you can wrap your head around all these issues?"

You're nod in affirmation, though, perhaps, with a bit less confidence than you wish you felt.

Your resident goes on to say, "Like most situations in clinical medicine and surgery, things will get better or they will get worse. And if they get worse, we'll just have to re-explore the patient here in the unit. You might be interested to know that we started doing these 'washouts' in the unit many years ago, when we realized that it was often quite challenging to get a patient back to the operating room expediently and that it was safe to do these procedures here in the unit. We'll talk a bit more about these issues in a moment." [Fiser, 2001 \& LaPar, 2014]

She then says, "Your main assignments are, therefore, to do your best with the interventions we've discussed and to recognize, in a timely way, if they are not working satisfactorily, which will allow us to get organized for an expeditious and safe washout."

Putting on your best game face, you assure her "I've got this ...”

\section{CARDIAC PHYSIOLOGY FOR DUMMIES}

"Great, that's the right answer. However," she goes on to say, "there's one last, simple, but very important, trick I want to tell you about." She then asks, "How good are you at math?" Puzzled, you claim to be fairly proficient with numbers. Your resident then asks you if you understand tamponade physiology. You say that you believe that you do, stating that you have learned that the decreased cardiac output in tamponade situations is caused by pressure on the heart that impairs the ability of the heart to fill during diastole.

"Bingo!" she exclaims, and then she asks, "How much fluid would you have to evacuate from the pericardial space to increase the cardiac output from, say, 1 liter per minute to 2 liters per minute, which would, obviously, double the cardiac output of such a patient?"

Since you look puzzled, she says "Let's say that the patient's heart rate is 100 and that you've drained that 10 milliliters of fluid from the pericardial space. If the heart can fill by an additional 10 milliliters in each cardiac cycle, you will have increased the cardiac output by 1 liter per minute, which is double the 1 liter per minute of cardiac output that is obviously too low to sustain the patient for very long. Your patient can be adequately, though barely, perfused with a cardiac output of 2 liters per minute, while he cannot be adequately perfused at 1 liter per minute." You acknowledge that you understand the validity of this concept. 


\section{RE-EXPLORATION FOR BEGINNERS}

"So," you ask, "should I be prepared to do a pericardiocentesis?"

"Heavens no!" she exclaims. "Even skilled interventionists cannot do that safely or effectively in this setting. As I was saying, all you need to do is to get 10 milliliters or more of 'free or loose blood' out of the pericardial space, though you'll probably evacuate a good bit more. And you will usually have bought enough time for me to get back here to do a proper washout."

Your resident continues, "Now, there may also be times when even this maneuver is not enough, and you will need to take out the sternal wires to lessen the pressure on the heart. A savvy resident like you seem to be should be able to take out the sternal wires and, in dire circumstances when you sense that you need to do even more, you can carefully lift up the sternal edges and pack some sponges around an area that seems to be bleeding briskly or put a finger on a specific site, such as an aortic cannulation site."

You nod in understanding, while heaving a sigh of relief at how controlled that approach sounds, especially since it sounds as though it might obviate the need for you to do something heroic on your own.

\section{THE FIVE TAKE-HOME LESSONS}

Finally, as your resident stands to leave, she says "Now, what are five important and somewhat surprising things you've learned this afternoon about dealing with a patient with ongoing bleeding after heart surgery?"

You agree to take a stab at summarizing what she has told you and you say that you will:

- Keep the hematocrit normal or close to normal.

- Get the patient warmed expeditiously to 37.5 degrees

- Control the blood pressure, without using antiplatelet medications.

- Follow a checklist.

- And, if the patient seems to be developing tamponade, remove a few stitches to allow at least some blood to drain until more experienced people can arrive.

"Bingo," she says. "I think we may have the makings of a surgical intensivist here!"

\section{Communication Breakdown (it's always the same ....)} _Led Zeppelin, 1969

As you now find yourself feeling at least a bit better about your strategies for the evening, she picks up her cup of coffee and begins to walk out but turns to say: "Oh, one more thing: we need to exchange cell numbers so that I can check in with you intermittently and so that you know, for sure, that you can call me about any issues, at any time."

You find yourself comforted not only by this information your chief has provided but by her assertion that you can call her at any time, day or night, for advice and support. And, you conclude, maybe this job is not quite as daunting as you had imagined, now that you understand these basic strategies.

\section{SUMMARY}

There are a surprising number of very important principles to keep in mind and strategies to employ in a patient who is bleeding after a cardiac surgical operation. And, it is incumbent on the more experienced members of the cardiac surgery team to ensure that the ICU residents and nurses are fully versed in these strategies.

\section{REFERENCES}

Tribble C, Merrill W. 2016. In Your Own Words: Towards a More Perfect Union of Patient Care and Education. Ann Thorac Surg 101: 837-40.

Tribble C. 2017. Grandmother Rules: Crucial Conversations with Patients and Families. Heart Surgery Forum 20(1): 1 - 5 .

I Corinthians 13: 13. https://www.bible.com/bible/1/1CO.13.KJV (Accessed 12-3-21)

von Hippel A. 1970. Chest Tubes and Chest Bottles. Charles C. Thomas Publisher. Springfield, IL.

Elefteriades J, Tribble C, Geha A, Siegal M, Cohen L. 2013. The House Officer's Guide to ICU Care, Third Edition. Cardiotext Publishing, LLC, Minneapolis, MN.

Clark D, Tesseneer S, Tribble C. 2012. Nitroglycerin and Sodium Nitroprusside: Potential Contributors to Postoperative Bleeding? Heart Surgery Forum 15 (2): E92 - E96.

Cope J, Banks D, Mauney M, Lucktong A, Shockey K, Kron I, Tribble C. 1997. Intraoperative hetastarch infusion impairs hemostasis after cardiac operations. Ann Thorac Surg 63: 78-83.

Gersh K, Nagaswami C, Weisel J. 2009. Fibrin network structure and clot mechanism properties are altered by incorporation of erythrocytes. Thromb Haemost 102 (6): 1169-75.

Cines D, Lebedeva T, Nagaswami C, Hayes V, Massefski W, Litvinov R, Rauova L, Lowery T, Weisel J. 2014.Clot contraction: compression of erythrocytes into tightly packed polyhedra and redistribution of platelets and fibrin. Blood 123(10):1596-1603.

Tibi P, McClure R, Huang J, Baker R et al. 2021. STS/SCA/AmSECT/ SABM Update to the Clinical Practice Guidelines on Patient Blood Management. Ann Thorac Surg 112 (3): 981-1004.

Holcomb J, Tilley B, Baraniuk S, et al. 2015. Transfusion of Plasma, Platelets, and Red Blood Cells in a 1:1:1 vs 1:1:2 Ratio and Morality in Patients with Severe Trauma. JAMA 313(5): 471-482.

Hess J. 2021. Massive Blood Transfusion. UpToDate. https://www.uptodate.com/contents/massive-blood-transfusion? topicRef $=7920 \&$ source $=$ see_link (Accessed 11-24-21)

Salzman E, Weinstein M, Weintraub R, Ware J, Thurer R, Robertson L, Donovan A, Gaffney T, Bertele V, Troll J, Smith M, Chute L. 1986. Treatment with Desmopressin Acetate to Reduce Blood Loss after Cardiac Surgery. N Engl J Med 314:1402-140

Calland J, Guerlain S, Adams R, Tribble C, Foley E, Chekan E. 2002. A systems approach to surgical safety. Surg Endosc 16 (6): 1005-14. 
Fiser SM, Tribble CG, Kern JA, Long SM, Kaza AK, Kron IL. 2001. Cardiac reoperation in the intensive care unit. Ann Thorac Surg 71: 1888-93.

LaPar D, Isbell J, Mulloy D, Stone M, Kern J, Ailawadi G, Kron I. 2014. Ann Thorac Surg 98: 1645-51.

Led Zeppelin. 1969. Communication Breakdown. Genius Lyrics: https:// genius.com/Led-zeppelin-communication-breakdown-lyrics (Accessed 11-24-21)

\section{ADDITIONAL RESOURCES}

Levy J. 2019. Post-operative Bleeding in the Cardiac Surgical Patient. https://www.youtube.com/watch?v=4Mw-3j7ADcY (Accessed 11-24-21)

\section{AUTHORS}

Dr. Tribble and Dr. Teman are Associate Program Directors for the Thoracic Surgery Residency at The University of Virginia. Both are board certified in Surgery, Surgical Critical Care, and Thoracic Surgery. Dr. Teman is the medical director of the cardiothoracic surgical intensive care unit at The University of Virginia.

Dr. Pham trained in Surgery and in Trauma / Critical Care Surgery at The University of Mississippi, and he is currently participating in a one year fellowship in Thoracic Surgery at the University of Virginia. 